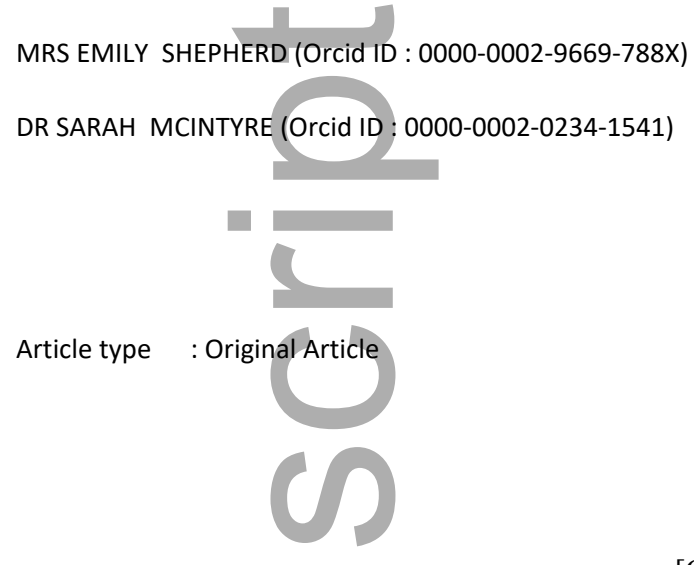

[Original article: 2 tables; 2 online tables]

Linking data from a large clinical trial with the Australian Cerebral Palsy Register

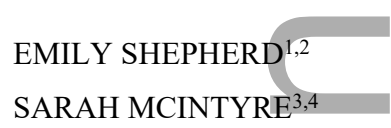

HAYLEY SMITHERS-SHEEDY ${ }^{3,4}$

PAT ASHWOOD ${ }^{2}$

THOMAS R SULLIVAN 1,5

ANNA TE VELDE 3,4

LEX W DOYLE $6,7,8,9$

MARIA MAKRIDES ${ }^{1,10}$

PHILIPPA MIDDLETON ${ }^{1,2}$

CAROLINE A CROWTHER ${ }^{2,11}$

1 SA Health and Medical Research Institute, Adelaide, SA; 2 Discipline of Obstetrics and Gynaecology, Adelaide Medical School, The University of Adelaide, Adelaide, SA; 3 Cerebral Palsy Alliance, Discipline of Child and Adolescent Health, The University of Sydney, Sydney, NSW; 4 Discipline of Child and Adolescent Health, Faculty of Medicine and Health, The University of Sydney, Sydney, NSW; 5 School of Public Health, The University of Adelaide, Adelaide, SA; 6 Victorian Infant Brain Studies, The Murdoch Children's Research Institute, Melbourne, Vic; 7 Neonatal Services, Royal Women's Hospital, Melbourne, Vic; 8 Department of Obstetrics and Gynaecology, The University of This is the author manuscript accepted for publication and has undergone full peer review but has not been through the copyediting, typesetting, pagination and proofreading process, which may lead to differences between this version and the Version of Record. Please cite this article as doi: 10.1111/DMCN.14556

This article is protected by copyright. All rights reserved 
Melbourne, Melbourne, Vic; 9 Department of Paediatrics, The University of Melbourne, Melbourne, Vic; 10 Discipline of Paediatrics, Adelaide Medical School, The University of Adelaide, Adelaide, SA, Australia. 11 Liggins Institute, The University of Auckland, Auckland, New Zealand.

Correspondence to Emily Shepherd, Level 7, Clarence Rieger Building, Women's and Children's Hospital, 72 King William Road, North Adelaide, South Australia 5006, Australia. E-mail: emily.shepherd@adelaide.edu.au

\section{PUBLICATION DATA}

Accepted for publication 00th Month 2019.

Published online 00th Month 2019.

\section{ABBREVIATIONS}

ACPR Australian Cerebral Palsy Register

$\mathrm{ACTOMgSO}_{4}$ Australasian Collaborative Trial of Magnesium Sulphate

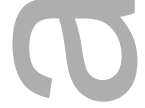

AIM To link data from a large maternal perinatal trial with the Australian Cerebral Palsy Register (ACPR) to identify children with cerebral palsy (CP).

METHOD Deidentified data from the Australasian Collaborative Trial of Magnesium Sulphate $\left(\mathrm{ACTOMgSO}_{4}\right)$ and the ACPR were linked. Children born from 1996 to 2000 at Australian hospitals who survived and had 2-year paediatric assessments were included. Children identified with CP in: (1) both the $\mathrm{ACTOMgSO}_{4}(2 \mathrm{y})$ and the ACPR (5y), (2) the $\mathrm{ACTOMgSO}_{4}$ only, and (3) the ACPR only were compared.

RESULTS We included 913 children (492 males, 421 females; mean gestational age at birth $27.8 \mathrm{wks}$ [standard deviation $2.1 \mathrm{wks}$ ]; range $23.0-40.0 \mathrm{wks}$ ). Eighty-four children received a CP diagnosis: 35 by the $\mathrm{ACTOMgSO}_{4}$ and the ACPR, 29 by the $\mathrm{ACTOMgSO}_{4}$ only, and 20 by the ACPR only. The $\mathrm{ACTOMgSO}_{4}$ diagnosed $76.2 \%$ (95\% confidence interval [CI] 65.984.1) and the ACPR identified 65.5\% (95\% CI 54.7-74.9). Children born in states/territories with long-standing versus more recently established registers were more likely to be included on the ACPR $(p<0.05)$.

INTERPRETATION Linking deidentified perinatal trial data with the ACPR was achieved. Limitations of both strategies for identifying children with CP in this era (late 1990s and early 2000s) probably explain many of the differences observed, and inform future linkage studies and evaluations of CP-preventive interventions.

This article is protected by copyright. All rights reserved 
[First page footer]

(C) Mac Keith Press 2020

DOI: $10.1111 / \mathrm{dmcn} \cdot \mathrm{xxxxx}$

[Left page footer]

Developmental Medicine \& Child Neurology 2020, 62: 000-000

[Right page footer]

Trial and Australian CP Register Linkage Emily Shepherd et al.

[Boxed text on page 2]

\section{What this paper adds}

- Randomized trial data were linked with the Australian Cerebral Palsy Register.

- Trial (2y) and register (up to 5y) diagnoses of cerebral palsy (CP) differed.

- States with long-standing registers were more likely to include children with $\mathrm{CP}$.

\section{[Main text]}

Long-term follow-up of maternal perinatal interventions is crucial, with many neurodevelopmental disabilities and other morbidities associated with perinatal complications only becoming apparent in, or beyond, childhood. ${ }^{1}$ However, only a minority of randomized trials assessing such interventions are able to report on long-term neurodevelopmental health, including cerebral palsy (CP). In a systematic review of 249 perinatal intervention trials, only $40(16 \%)$ reported outcomes beyond the initial neonatal hospital discharge. ${ }^{2}$ Although there is increasing recognition of the importance of assessing longer-term outcomes, ${ }^{1,3}$ follow-up rates remain low. ${ }^{2}$ In a systematic review of 22 Cochrane studies of interventions in infants at risk of CP, 'neurodevelopmental outcomes' (e.g. CP, blindness, deafness, intellectual impairment) were the second most frequently reviewed outcomes of interest. ${ }^{4}$ Only a minority of included randomized trials (22 out of $203,11 \%$ ), however, reported these data. ${ }^{4}$ Similarly, our own recent Cochrane overviews of reviews found that few relevant antenatal or intrapartum ${ }^{5}$ (15 out of $77,19 \%$ ) and neonatal ${ }^{6}$ (43 out of $145,30 \%$ ) randomized trials reported $\mathrm{CP}$ as an outcome.

Challenges associated with long-term follow-up are well recognized and numerous. Costs may be prohibitive or underestimated. ${ }^{7}$ Loss to follow-up may compromise interpretation of outcomes, as the children most difficult to follow-up are known to have comparatively poorer neurodevelopmental outcomes ${ }^{8,9}$ Further, follow-up methods, ages of assessment, and This article is protected by copyright. All rights reserved 
outcome definitions vary within and between trials., ${ }^{2,4-6}$ These hurdles in the meaningful evaluation of preventive strategies for adverse neurodevelopmental outcomes, including CP, have triggered growing interest in the use of alternative strategies to follow-up children from maternal perinatal intervention trials. One potential approach is linkage of trial data to routine/administrative data sets or disease-specific registries, ${ }^{10}$ such as the Australian Cerebral Palsy Register (ACPR).

Thus, we aimed to assess the utility of linking data from a large maternal perinatal clinical trial with the ACPR to identify children with CP. The Australasian Collaborative Trial of Magnesium Sulphate $\left(\mathrm{ACTOMgSO}_{4}\right)$ was a randomized trial assessing magnesium sulphate before very preterm birth, for preventing paediatric mortality and $\mathrm{CP}$, and was initially funded to follow-up children to these primary endpoints, at 2 years corrected age. ${ }^{11}$

\section{METHOD}

\section{Design}

The current study was a deidentified linkage of existing data from the $\mathrm{ACTOMgSO}_{4}$ and the ACPR.

\section{Participants and setting}

Full details of the ACTOMgSO 4 have been reported. ${ }^{11}$ Briefly, 1062 females with a singleton, twin, triplet, or quadruplet pregnancy at less than 30 weeks' gestation, for whom birth was planned or expected within 24 hours, were randomized at 16 maternity hospitals in Australia or New Zealand, between 1996 and 2000, either to intravenous magnesium sulphate $(n=535)$ or to saline placebo $(n=527)$. The pregnant females, health professionals, and outcome assessors were blinded to allocation. Of 1262 fetuses, 1255 were alive at randomization, and 1061 children survived to 2 years corrected age, where the primary outcomes of death, CP, and the combined outcome, death, or CP were determined. Surviving children were assessed by a developmental paediatrician and psychologist, and parents or caregivers completed questionnaires about their children's development. The criteria for CP included abnormalities of tone, deep tendon or Babinski reflexes, and impaired motor function. CP severity was described (before the Gross Motor Function Classification System ${ }^{12}$ ) as mild (disability in ambulant children interfering only slightly with normal daily activities), moderate (children attempting to walk at $2 \mathrm{y}$, with or without assisted devices), or severe (children likely to remain non-ambulant). ${ }^{13}$

For data linkage, we included children at 13 Australian hospitals, who survived, and who had paediatric assessments at 2 years. We excluded children born at three hospitals in New Zealand, who died before 2 years, or who did not have 2 -year paediatric assessments.

This article is protected by copyright. All rights reserved 


\section{Data collection and linkage}

Data from eligible children within the $\mathrm{ACTOMgSO}_{4}$ database were linked with ACPR data. Established in 2008, the ACPR is an electronic database, securely uploaded from each state and territory $\mathrm{CP}$ register. ${ }^{14}$ This includes data from long-standing $\mathrm{CP}$ registers in Western Australia (established in 1979), Victoria (1987), and South Australia (1998), and newer (as recently as 2006) registers in New South Wales/Australian Capital Territory, Queensland, Tasmania, and the Northern Territory. The processes for notification to add inclusion in the CP registers vary across states and territories in line with local ethics and legislative requirements. To be included in any CP register, a child's motor impairment must meet a definition for CP current at the time (as diagnosed by a health professional, commonly a paediatrician), which includes the following key elements: (1) an umbrella term for a group of disorders; (2) a condition that is permanent but not unchanging; (3) involves a disorder of movement and/or posture and of motor function; (4) caused by a non-progressive interference, lesion, or abnormality; (5) the interference, lesion, or abnormality originated in the immature brain. ${ }^{15,16}$ Children's CP is again 'confirmed' when they reach 5 years of age; thereafter records are considered 'complete'. Where new information becomes available, cases may be updated, leading to inclusion or exclusion. Along with monitoring CP incidence and prevalence, one of the ACPR's key aims is to facilitate the evaluation of preventive strategies. ${ }^{14}$

For data linkage, the $\mathrm{ACTOMgSO}_{4}$ coordinating centre provided the ACPR with a password-protected data set including the following variables for eligible children: (1) child's date of birth; (2) mother's date of birth; (3) child's hospital of birth; (4) child's birth order number (multiple births); (5) child's gestational age at birth (weeks and days); (6) child's birthweight (g). To ensure participant anonymity and confidentiality, personal details were not provided, and each child retained their unique $\mathrm{ACTOMgSO}_{4}$ identifier. Using multiple-step deterministic linkage procedures, ${ }^{17}$ the ACPR identified potential matches on the basis of the variables in the above order. Complete matches were individuals who matched on the first four variables. If there were missing data, the fifth and sixth variables were used. After extraction of the CP diagnoses from the register, the ACPR returned the data set.

\section{Statistical analysis}

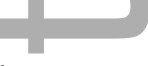

$\mathrm{CP}$ diagnoses were grouped by: (1) diagnosis in both the $\mathrm{ACTOMgSO}_{4}$ and on the ACPR, (2) in the $\mathrm{ACTOMgSO}_{4}$ only, and (3) on the ACPR only. We assessed CP diagnoses for all children, and separately for children born in states with long-standing versus more recently established CP registers. We used univariate logistic regression models to explore whether birth state/territory register status, and movement- and/or posture-related outcomes at the This article is protected by copyright. All rights reserved 
$\mathrm{ACTOMgSO}_{4}$ 2-year assessments, predicted later ACPR inclusion. Two-year outcomes included those from paediatric assessment (CP, including severity and type, not walking freely, decreased or increased limb tone, ankle clonus more than five beats, positive Babinski response, limited dorsiflexion of ankle, limited hip abduction, limited hip extension), psychological assessment (Psychomotor Developmental Index corrected score of the Bayley Scales of Infant Development, Second Edition), ${ }^{18}$ and parental questionnaire (receipt of care from physiotherapist or occupational therapist, difficulty walking, sitting, using hands, and with head control). The models were fitted separately according to $\mathrm{CP}$ status in the $\mathrm{ACTOMgSO}_{4}$ and used generalized estimating equations to account for clustering due to multiple births. Associations were described using odds ratios with $95 \%$ confidence intervals (CIs). Data were analysed in SPSS version 21.0 (IBM SPSS Statistics for Windows, IBM Corp., Armonk, NY, USA).

\section{Ethics approval and consent}

Ethical approval was granted by the Women's and Children's Health Network Human Research Ethics Committee (HREC/16/WCHN/18), and research governance by the Women's and Children's Hospital (SSA/16/WCHN/057). As conditions of 2.3.10 of the National Statement on Ethical Conduct in Human Research were met, and all families had given written informed consent to participate in the $\mathrm{ACTOMgSO}_{4},{ }^{11}$ a waiver of consent was approved. All state and territory $\mathrm{CP}$ register data custodians agreed to the use of ACPR data for linkage, and a waiver of consent was provided by the Cerebral Palsy Alliance Human Research and Ethics Committee (project waiver number 2016-03-01).

\section{RESULTS}

Of 1061 children who survived to 2 years corrected age, we excluded 135 born in New Zealand, and 13 who did not have 2-year paediatric assessments. We thus included 913 children. Their perinatal characteristics are presented in Table 1.

\section{CP diagnoses}

Of 913 eligible children, the $\mathrm{ACTOMgSO}_{4}$ diagnosed 64 (7.0\%) with $\mathrm{CP}$ at 2 years, and the ACPR identified $55(6.0 \%)$ children with $\mathrm{CP}$ at 5 years. Some children with $\mathrm{CP}$ diagnoses were identified by both the $\mathrm{ACTOMgSO}_{4}$ and the ACPR ( $\left.n=35\right)$, others only by the $\mathrm{ACTOMgSO}_{4}$ $(n=29)$ or only by the ACPR ( $n=20)$. Thus 84 children were identified with CP by the $\mathrm{ACTOMgSO}_{4}$ and/or the ACPR. The ACTOMgSO $\mathrm{Al}_{4}$ diagnosed $76.2 \%$ (95\% CI 65.9-84.1) of the 84 children, and the ACPR identified $65.5 \%$ (95\% CI 54.7-74.9). The remaining 829 children did not have CP diagnoses either by the $\mathrm{ACTOMgSO}_{4}$ or the ACPR (Table 2). This article is protected by copyright. All rights reserved 
Of 46 children with a CP diagnosis (by the $\mathrm{ACTOMgSO}_{4}$ and/or the ACPR) in states with long-standing $\mathrm{CP}$ registers, the $\mathrm{ACTOMgSO}_{4}$ diagnosed $65.2 \%$ (95\% CI 50.4-77.6) $(n=30)$, and the ACPR 80.4\% (95\% CI 66.4-89.5) ( $n=37)$. Of 38 children with CP diagnoses (by the $\mathrm{ACTOMgSO}_{4}$ and/or the ACPR) in states/territories with more recently established registers, the $\mathrm{ACTOMgSO}_{4}$ diagnosed $89.5 \%$ (95\% CI 75.1-96.0) $(n=34)$, and the ACPR identified 47.4\% (95\% CI 32.3-63.0) ( $n=18)$ (Table 2).

\section{Children with a CP diagnosis in the $\mathrm{ACTOMgSO}_{4}$}

Of 64 children with a $\mathrm{CP}$ diagnosis at 2 years in the $\mathrm{ACTOMgSO}_{4}$, those born in states with long-standing CP registers were more likely to be included on the ACPR (at 5y) than those born in states/territories with more recently established registers. Children judged to have a 'definitely yes' CP status at 2 years (versus a 'probably yes' CP status), with difficulty walking (paediatric assessment), and using their hands (parental assessment) were more likely to be included on the ACPR. No further associations between 2-year movement and/or posture outcomes assessed and ACPR inclusion at 5 years were observed (Table S1, online supporting information). Of the 29 children with a $\mathrm{CP}$ diagnosis in the $\mathrm{ACTOMgSO}_{4}$, not included on the ACPR, at 2 years, $19(65.5 \%)$ were judged to have 'mild', nine (31.0\%) 'moderate', and one (3.4\%) 'severe' CP; no clear association between CP severity and ACPR inclusion was observed, however.

\section{Children without a CP diagnosis in the $\mathrm{ACTOMgSO}_{4}$}

Of 849 children not diagnosed with CP at 2 years in the $\mathrm{ACTOMgSO}_{4}$, those born in states with long-standing CP registers were more likely to be included on the ACPR (at 5y) than those born in states/territories with more recently established registers (Table S2, online supporting information). Children with a 'definitely no' CP status at 2 years (vs a 'probably no' CP status) were less likely to be included on the ACPR. Difficulty walking (paediatric and parental assessments) and using hands (parental assessment), decreased limb tone and limited dorsiflexion of the ankle (paediatric assessment), and receipt of care from a physiotherapist or occupational therapist (parental report) were all associated with ACPR inclusion. Bayley Scales of Infant Development, Second Edition Psychomotor Developmental Index corrected score was associated with ACPR inclusion; children included on the ACPR had a lower mean score overall than those not on the ACPR. For the remaining outcomes assessed, no clear associations with ACPR inclusion at 5 years were observed (Table S2).

\section{DISCUSSION}

This article is protected by copyright. All rights reserved 
With increasing challenges of long-term maternal perinatal intervention follow-up, there is growing interest in the use of routine data or registries to assess child health and development. This approach may have important advantages, including relatively low cost compared with primary data collection in costly trial follow-up assessments. ${ }^{7,10} \mathrm{We}$ report the first data linkage of a large maternal perinatal clinical trial $\left(\mathrm{ACTOMgSO}_{4}\right)$ with a nationwide $\mathrm{CP}$ register (ACPR) to identify children with $\mathrm{CP}$.

Of almost 1000 Australian children included in this study (born 1996-2000), the $\mathrm{ACTOMgSO}_{4}$ diagnosed 64 with $\mathrm{CP}$ at 2 years, and linkage with the ACPR identified 55 children to have $\mathrm{CP}$ up to 5 years. In total, 84 children were identified to have a $\mathrm{CP}$ diagnosis in the $\mathrm{ACTOMgSO}_{4}$ and/or via the ACPR. Using these data, prevalence rates of CP ranged from $6.0 \%$ to $9.2 \%$; comparable to recently reported Australian birth prevalence rates for similar gestational ages and years. ${ }^{19}$

Although we successfully linked these data, we did identify notable discrepancies in children diagnosed with $\mathrm{CP}$ through the $\mathrm{ACTOMgSO}_{4}$ and those identified by the ACPR, with only $42 \%(n=35)$ of the $84 \mathrm{CP}$ diagnoses considered 'matches'. Findings of exploratory analyses (assessing whether birth state/territory status, and movement and/or posture-related outcomes at the ACTOMgSO 4 2-year assessments predicted later ACPR inclusion) should be interpreted with caution; small numbers led to relatively imprecise results. Limitations in both strategies for identifying children with CP in the late 1990s may account for the differences and warrant discussion.

The $\mathrm{ACTOMgSO}_{4}$ diagnosed 29 children with $\mathrm{CP}$ who were not on the ACPR; there are a variety of potential reasons. While the three long-standing registers (established before 1998) have achieved population-level ascertainment, the remaining registers (established as recently as 2006 - well after trial completion) are considered under-ascertained. ${ }^{14}$ Although notable gains have been made in retrospective case ascertainment by these newer registers, for the relevant birth years, there are probably some 'missing' cases/matches. ${ }^{14,19}$ In line with this, we observed an association between register status and ACPR inclusion, with children (with and without $\mathrm{ACTOMgSO}{ }_{4} \mathrm{CP}$ diagnoses) born in states with long-standing $\mathrm{CP}$ registers being more likely to be included on the ACPR.

Missing ACPR data for variables used for linkage (such as gestational age at birth and birthweight) in these earlier birth years, and our obligation to ensure participant anonymity and confidentiality, precluded the determination of a small number $(n=2)$ of potential 'matches'. From the under-ascertained registers, there were ACPR registrations with complete CP data, but missing data on all/many linkage variables, preventing any matching. Thus, linking with identifiable data would have facilitated this study. It is possible that some children with a diagnosis in the $\mathrm{ACTOMgSO}_{4}$ were 'considered' for ACPR registration, but ultimately not This article is protected by copyright. All rights reserved 
included on the ACPR; deidentified linkage also precluded knowledge of this. Underascertainment by the ACPR could also relate to factors including relocation of families internationally; however, we were not able to quantify the impact of such losses to follow-up in this deidentified study. With continued improvements in ACPR ascertainment and considerably fewer missing data with prospective data collection, these factors may be less important in future linkages with contemporary trial cohorts.

Beyond ACPR data limitations for relevant birth years, possible reasons for differences observed relate to the descriptive nature of a $\mathrm{CP}$ diagnosis, and shortcomings of diagnostic methods used at the time. CP is an umbrella term, covering different clinical manifestations and aetiologies. Registers contributing to the ACPR only consider cases 'confirmed' when children reach 5 years of age, ${ }^{14}$ acknowledging that new information (or different interpretation of information) may lead to alternative diagnoses or exclusion. The possibility of diagnosis reversal is well recognized, particularly for high risk, children born preterm-'motor abnormalities detected in early childhood may subsequently lessen in degree, change in kind, or disappear altogether' ${ }^{20}$ Previous studies, including those from the South Australian ${ }^{21}$ and Canadian ${ }^{22} \mathrm{CP}$ registers, have highlighted small proportions of children with $\mathrm{CP}$ notifications, later confirmed to have non-CP diagnoses, for example, progressive genetic conditions or syndromes and metabolic diseases excluded by definition, and developmental or gross motor delay. In 2016, Korzeniewski et al. described the 'transient' nature of a CP diagnosis, with 40\% (17 out of 43) of children with 'non-disabling' CP at 2 years having CP at school age (6-9y), compared with $98 \%$ ( 47 out of 48 ) of those with 'disabling' CP. ${ }^{23}$ In contrast, Chen et al. found no association between CP motor severity and loss of a diagnosis over time (between $2 \mathrm{y}$ and $5 y)$ among 1683 children with a Canadian CP Registry notification. ${ }^{22}$ In our study, although we did not observe an association between CP severity at 2 years and later ACPR inclusion, of note $66 \%$ (19/29) of children diagnosed with $\mathrm{CP}$ in the $\mathrm{ACTOMgSO}_{4}$, not subsequently on the ACPR, were considered to have mild CP.

An important further explanation for the differences observed relates to improvements in diagnostic methods used. Today, a CP diagnosis (including interim use of a 'high risk of CP' diagnosis) can be made according to recommendations within 2017 international clinical practice guidelines. ${ }^{24}$ Where appropriate, including with congruence of findings, a diagnosis is possible under the age of 6 months using predictive tools. As there is no single diagnostic tool, a combination of clinical history, neuroimaging (magnetic resonance imaging, 86-89\% sensitivity), standardized neurological assessments (such as the Hammersmith Infant Neurological Examination, 90\% sensitivity), and standardized motor assessments (particularly Prechtl's Qualitative Assessment of General Movements before 5mo corrected age, 98\% sensitivity) are suggested, to make the most accurate, earliest diagnosis..$^{24,25}$

This article is protected by copyright. All rights reserved 
While the importance of early diagnosis, particularly for facilitating early intervention, is now recognized, traditionally a CP diagnosis was made much later. ${ }^{24,25} \mathrm{~A}$ 'wait and see' approach was common (up to and beyond the perceived 'latent' period of 12-24mo, where it was believed $\mathrm{CP}$ could not be identified accurately ${ }^{24}$ ), providing time 'to rule out other diagnoses, delay the delivery of bad news or provide time for the child to grow out of it' ${ }^{26}$ Within the $\mathrm{ACTOMgSO}$, $\mathrm{CP}$ diagnoses were made at a single paediatric examination at 2 years. ${ }^{13}$ While being the most accurate available approach, it has recognized limitations. We observed associations between CP status at 2 years in the $\mathrm{ACTOMgSO}_{4}$ ('probably yes' vs 'definitely yes' for CP diagnoses; and 'probably no' vs 'definitely no' for non-CP diagnoses) and later ACPR inclusion at 5 years, emphasizing difficulties in making firm diagnoses in the late 1990 s and early 2000 s

The ACPR identified 20 children with CP not diagnosed at 2 years in the $\mathrm{ACTOMgSO}_{4}$. We found associations between a variety of possible indicators of movement and/or posture dysfunction at 2 years in the $\mathrm{ACTOMgSO}_{4}$ and subsequent $\mathrm{ACPR}$ inclusion at 5 years. For example, children without $\mathrm{CP}$ diagnoses in the $\mathrm{ACTOMgSO}_{4}$, but with parental reports of difficulty walking and using their hands, who received care from physiotherapists and/or occupational therapists, were more likely to be on the ACPR. This may represent the presence of 'milder' degrees of motor dysfunction among these children, not sufficient to flag $\mathrm{CP}$ diagnoses at the time of the trial, in the context of the previously discussed diagnostic limitations.

Our study provides a firm basis for further linkages of clinical trials with the ACPR for childhood follow-up. All ACPR contributing registers are expected to achieve population-level ascertainment in the coming years, and further research on the use of ACPR CP diagnoses for long-term outcome assessment in preventive trials is recommended. Future trials assessing preventive interventions for CP should consider pre-specification of linkage with CP register data in their protocols, participant information sheets, and consent forms, enabling the use of identifiable data. Maternal perinatal trials assessing $\mathrm{CP}$ are urged to follow the international clinical practice guidelines for early, accurate diagnosis..$^{24}$

\section{CONCLUSION}

We have conducted the first deidentified data linkage of a large maternal perinatal randomized trial with the ACPR. Limitations of both strategies in the late 1990s and early 2000s for identifying children with $\mathrm{CP}$ probably explain many of the differences observed (with fewer than half of all CP diagnoses identified by both the trial and the ACPR). Further linkage studies, of contemporary trial cohorts, will progress our understanding of the 'criterion standard' strategy for assessing long-term follow-up of $\mathrm{CP}$ after maternal perinatal interventions; and, This article is protected by copyright. All rights reserved 
together with recent advances in early, accurate CP diagnosis, they will aid in the future evaluation of preventive strategies.

\section{ACKNOWLEDGEMENTS}

We thank members of the ACPR Group, and the families of both the ACPR and the $\mathrm{ACTOMgSO}_{4}$. This research received no specific grant from any funding agency in the public, commercial, or not-for-profit sectors. The authors have stated that they had no interests that might be perceived as posing a conflict or bias.

\section{SUPPORTING INFORMATION}

The following additional material may be found online:

Table S1: Birth state/territory CP register status and 2-year outcomes for children with a CP diagnosis in the $\mathrm{ACTOMgSO}_{4}$

Table S2: Birth state/territory CP register status and 2-year outcomes for children without a $\mathrm{CP}$ diagnosis in the $\mathrm{ACTOMgSO}_{4}$

\section{REFERENCES}

1. Doyle LW, Saigal S. Long-term outcomes of very preterm or tiny infants. NeoReviews 2009; 10: e130-e7.

2. Teune MJ, van Wassenaer AG, Malin GL, et al. Long-term child follow-up after large obstetric randomised controlled trials for the evaluation of perinatal interventions: a systematic review of the literature. BJOG 2013; 120: 15-22.

3. van't Hooft J, Duffy JM, Daly M, et al. A core outcome set for evaluation of interventions to prevent preterm birth. Obstet Gynecol 2016; 127: 49-58.

4. Hines M, Swinburn K, McIntyre S, Novak I, Badawi N. Infants at risk of cerebral palsy: a systematic review of outcomes used in Cochrane studies of pregnancy, childbirth and neonatology. J Matern Fetal Neonatal Med 2015; 28: 1871-83.

5. Shepherd E, Salam RA, Middleton $P$, et al. Antenatal and intrapartum interventions for preventing cerebral palsy: an overview of Cochrane systematic reviews. Cochrane Database Syst Rev 2017; 8: CD012077.

6. Shepherd E, Salam RA, Middleton P, et al. Neonatal interventions for preventing cerebral palsy: an overview of Cochrane systematic reviews. Cochrane Database Syst Rev 2018; 6: CD012409

7. Doyle LW, Clucas L, Roberts G, et al. The cost of long-term follow-up of high-risk infants for research studies. J Paediatr Child Health 2015; 51: 1012-6.

This article is protected by copyright. All rights reserved 
8. Callanan C, Doyle L, Rickards A, et al. Children followed with difficulty: how do they differ? J Paediatr Child Health 2001; 37: 152-6.

9. Doyle LW, Anderson PJ, Burnett A, et al. Developmental disability at school age and difficulty obtaining follow-up data. Pediatrics 2018; 141: e20173102.

10. McCord KA, Al-Shahi Salman R, Treweek S, et al. Routinely collected data for randomized trials: promises, barriers, and implications. Trials 2018; 19: 29.

11. Crowther CA, Hiller JE, Doyle LW, Haslam RR, for the Australasian Collaborative Trial of Magnesium Sulphate Collaborative Group. Effect of magnesium sulfate given for neuroprotection before preterm birtha randomized controlled trial. JAMA 2003; 290: 2669-76.

12. Palisano R, Rosenbaum $P$, Walter $S$, et al. Development and reliability of a system to classify gross motor function in children with cerebral palsy. Dev Med Child Neurol 1997; 39: 214-23.

13. Kitchen WH, Doyle LW, Ford GW, et al. Cerebral palsy in very low birthweight infants surviving to 2 years with modern perinatal intensive care. Am J Perinatol 1987; 4: 29-35.

14. Australian Cerebral Palsy Register (ACPR) Group. Report of the Australian Cerebral Palsy Register. Birth Years 1995-2012. Sydney: ACPR, 2018.

15. Surveillance of Cerebral Palsy in Europe (SCPE). Surveillance of cerebral palsy in Europe: a collaboration of cerebral palsy surveys and registers. Dev Med Child Neurol 2000; 42: 816-24.

16. Rosenbaum P, Paneth N, Leviton A, et al. A report: the definition and classification of cerebral palsy April 2006. Dev Med Child Neurol Suppl 2007; 109: 8-14.

17. Dusetzina SB TS, Meyer AM, et al. Linking Data for Health Services Research: A Framework and Instructional Guide. Rockville, MD: Agency for Healthcare Research and Quality, 2014.

18. Bayley N. Bayley Scales of Infant Development (2nd edition). Manual. San Antonio, TX: Psychological Corporation; 1993.

19. Galea C, McIntyre S, Smithers-Sheedy H, et al. Cerebral palsy trends in Australia (19952009): a population-based observational study. Dev Med Child Neurol 2019; 61: 186-93.

20. Nelson KB, Ellenberg JH. Children who 'outgrew' cerebral palsy. Pediatrics 1982; 69: 529-36.

21. Zarrinkalam R, Russo RN, Gibson CS, et al. CP or not CP? A review of diagnoses in a cerebral palsy register. Pediatr Neurol 2010; 42: 177-80.

22. Chen A, Dyck Holzinger S, Oskoui M, Shevell M. Losing a diagnosis of cerebral palsy: a comparison of variables at 2 and 5 years. Dev Med Child Neurol 2020; 62: 83-8.

This article is protected by copyright. All rights reserved 
23. Korzeniewski SJ, Feldman JF, Lorenz JM, Pinto-Martin JA, Whitaker AH, Paneth N. Persistence of cerebral palsy diagnosis: assessment of a low-birth-weight cohort at ages 2, 6, and 9 years. J Child Neurol 2016; 31: 461-7.

24. Novak I, Morgan C, Adde L, et al. Early, accurate diagnosis and early intervention in cerebral palsy: advances in diagnosis and treatment. JAMA Pediatr 2017; 171: 897-907.

25. Spittle AJ, Morgan C, Olsen JE, Novak I, Cheong JLY. Early diagnosis and treatment of cerebral palsy in children with a history of preterm birth. Clin Perinatol 2018; 45: 40920.

26. McIntyre S, Morgan C, Walker K, Novak I. Cerebral palsy—don't delay. Dev Disabil Res Rev 2011; 17: 114-29.

Table 1: Perinatal characteristics of $\mathrm{ACTOMgSO}_{4}$ children eligible for linkage

\begin{tabular}{ll}
\hline Characteristic & $\begin{array}{l}\text { Eligible } \mathrm{ACTOMgSO}_{4} \\
\text { children }(n=913)\end{array}$ \\
\hline $\begin{array}{l}\text { Mean gestational age (SD) at birth, } \\
\text { completed wks }\end{array}$ & $27.8(2.1)$ \\
Preterm birth $<30 \mathrm{wks}$ & $872(95.5)$ \\
Preterm birth $<37$ wks & $905(99.1)$ \\
Mean birthweight (SD), g & $1079.4(375.4)$ \\
Male sex & $492(53.9)$ \\
Multiple pregnancy & $262(28.7)$
\end{tabular}

Data are $n(\%)$ unless otherwise specified. ACTOMgSO 4 , Australasian Collaborative Trial of Magnesium Sulphate; SD, standard deviation.

Table 2: Diagnoses of cerebral palsy (CP) in $\mathrm{ACTOMgSO}_{4}$ at 2 years, and on ACPR at 5 years

\begin{tabular}{|c|c|}
\hline Australian children from $\mathrm{ACTOMgSO}_{4}(n=913)$ & $n(\%)$ \\
\hline CP diagnosis (any) & $84(9.2)$ \\
\hline $\mathrm{CP}$ in $\mathrm{ACTOMgSO}_{4}$ and on $\mathrm{ACPR}$ & 35 \\
\hline $\mathrm{CP}$ in $\mathrm{ACTOMgSO}_{4}$ only & 29 \\
\hline $\mathrm{CP}$ on ACPR only & 20 \\
\hline No CP diagnosis & $829(90.8)$ \\
\hline Children born in states with long-standing CP registers from $\mathrm{ACTOMgSO}_{4}(n=449)$ & $n(\%)$ \\
\hline $\mathrm{CP}$ diagnosis (any) & $46(10.2)$ \\
\hline $\mathrm{CP}$ in $\mathrm{ACTOMgSO}_{4}$ and on $\mathrm{ACPR}$ & 21 \\
\hline
\end{tabular}

This article is protected by copyright. All rights reserved 
$\begin{array}{ll}\mathrm{CP} \text { in } \mathrm{ACTOMgSO}_{4} \text { only } & 9 \\ \mathrm{CP} \text { on ACPR only } & 16\end{array}$

No CP diagnosis

16

403 (89.8)

Children born in states/territories with more recently established CP registers from

$n(\%)$

$\mathrm{ACTOMgSO}_{4}(n=464)$

$\mathrm{CP}$ diagnosis (any) $38(8.2)$

$\mathrm{CP}$ in $\mathrm{ACTOMgSO}_{4}$ and on $\mathrm{ACPR}$

14

$\mathrm{CP}$ in $\mathrm{ACTOMgSO}_{4}$ only

20

$\mathrm{CP}$ on ACPR only

4

No CP diagnosis

426 (91.8)

$\mathrm{ACTOMgSO}_{4}$, Australasian Collaborative Trial of Magnesium Sulphate; ACPR, Australian

Cerebral Palsy Register.

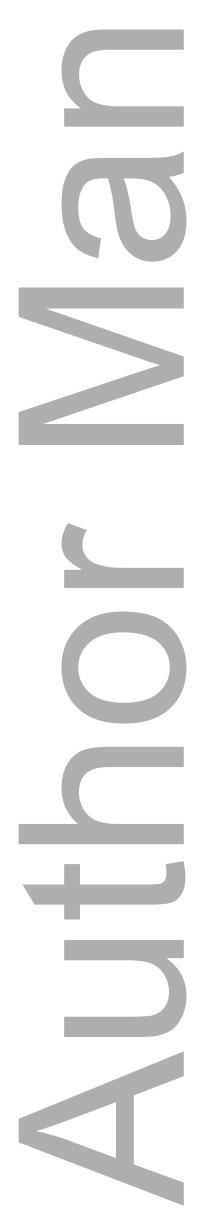

This article is protected by copyright. All rights reserved 


\section{University Library}

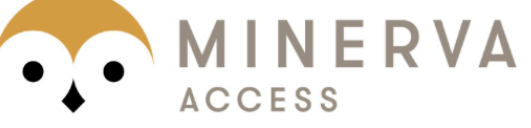

A gateway to Melbourne's research publications

Minerva Access is the Institutional Repository of The University of Melbourne

Author/s:

Shepherd, E;Mcintyre, S;Smithers-Sheedy, H;Ashwood, P;Sullivan, TR;Te Velde, A;Doyle, LW;Makrides, M;Middleton, P;Crowther, CA

Title:

Linking data from a large clinical trial with the Australian Cerebral Palsy Register

Date:

2020-10

\section{Citation:}

Shepherd, E., Mcintyre, S., Smithers-Sheedy, H., Ashwood, P., Sullivan, T. R., Te Velde, A., Doyle, L. W., Makrides, M., Middleton, P. \& Crowther, C. A. (2020). Linking data from a large clinical trial with the Australian Cerebral Palsy Register. DEVELOPMENTAL MEDICINE AND CHILD NEUROLOGY, 62 (10), pp.1170-1175. https://doi.org/10.1111/dmcn.14556.

Persistent Link:

http://hdl.handle.net/11343/275724 